\title{
Spatial and temporal changes in invertebrate assemblage structure from the entrance to deep-cave zone of a temperate marble cave
}

\author{
Benjamin W. Tobin*, Benjamin T. Hutchins, and Benjamin F. Schwartz \\ Texas State University - San Marcos, Department of Biology, 601 University Drive, San Marcos, TX 78666-4684
}

\begin{abstract}
Seasonality in surface weather results in seasonal temperature and humidity changes in caves. Ecological and physiological differences among trogloxenes, troglophiles, and troglobionts result in species-dependent responses to this variability. To investigate these responses, we conducted five biological inventories in a marble cave in the Sierra Nevada Range, California, USA between May and December 2010. The cave was divided into six quadrats and temperature was continuously logged in each (humidity was logged at the entrance and in the deep cave). With increasing distance from the entrance, temperature changes were increasingly attenuated and lagged relative to surface temperature. Linear regressions were created to determine the relationship between measured environmental variables and diversity for cavernicoles (troglobionts and troglophiles) and trogloxenes cavewide and in the transition zone. Diversity for cavernicoles and trogloxenes peaked in the entrance and deep cave zones, respectively. Quadrat, date, 2-week antecedent temperature average, 2-week antecedent temperature range, and trogloxene abundance explained $76 \%$ of cavernicole diversity variability. Quadrat explained $55 \%$ of trogloxene diversity variability. In the transition zone, trogloxene abundance explained $26 \%$ of cavernicole variability and 2-week antecedent temperature and 2-week antecedent temperature range explained $40 \%$ of trogloxene variability. In the transition zone, trogloxene diversity was inversely related to 2-week antecedent temperature average and 2-week antecedent temperature range, suggesting that species were moving into the transition zone when temperature was most stable. In a CCA of cavernicoles distribution data and environmental variables, 35\% of variation in species-specific distributions was attributable to quadrat, and non-significant percentages were explained by date and environmental variables. Differences in assemblage structure among quadrats were largely due to differences between distributions of trogloxenes and cavernicoles, but responses varied among species. Differences are likely due to ecological niche width, physiological constraints, and competition.
\end{abstract}

Keywords: $\quad$ cave climate; troglobiont; troglophile; Sequoia National Park, California, USA; community response; species interaction

Received 31 January 2013; Revised 28 June 2013; Accepted 9 July 2013

Citation: Tobin B.W., Hutchins B.T. and Schwartz B.F., 2013. Spatial and temporal changes in invertebrate assemblage structure from the entrance to deep-cave zone of a temperate marble cave. International Journal of Speleology, 42 (3), 203-214. Tampa, FL (USA) ISSN 0392-6672 http://dx.doi.org/10.5038/1827-806X.42.3.4

\section{INTRODUCTION}

Spatial heterogeneity in the distribution of species at local scales within caves and other subterranean habitats has long been documented (Racoviță, 2006). This heterogeneity has been attributed to resource availability (Barr \& Kuehne, 1971; Poulson, 2005), microclimate variability (Barr \& Kuehne, 1971; Howarth, 1980; Culver, 2005a; Pipan et al., 2006), invasion history (Fong \& Culver, 1994), and species interactions (Culver, 1970, 2005b;
Culver et al., 1991). However, despite a shift away from the old paradigm that subterranean habitats are temporally stable, little research has focused on quantifying and explaining temporal variability in the distribution of invertebrates found in caves. In most, if not all caves, seasonality on the surface affects the velocity, direction, and daily oscillations of barometric and chimney-effect airflow, resulting in seasonal trends in cave humidity and temperature (Howarth, 1980; Cigna, 2002). Cave morphology, vertical position of entrance/s relative to the 
rest of the cave, and changing surface conditions create seasonal drying near an entrance when air flows into the cave and a seasonal increase in humidity near an entrance when air flows out of the cave. Variability in these seasonal patterns is typically reduced deeper into the cave.

Based on environmental conditions and environmental variability, cave habitats can be divided into three primary zones: 1) an entrance area that is climatically variable and strongly affected by changes in the surface environment, 2) a deep cave zone that is characterized by relatively stable temperature, and humidity at or near saturation, and 3) a transition zone that seasonally displays characteristics of either the entrance or deep cave zone. The spatial extents of these zones vary among caves and are primarily determined by passage morphology and airflow patterns.

Troglobionts (obligate subterranean species) are typically assumed to be stenothermic (adapted to a narrow range of temperatures) and stenohygrobic (restricted to areas with nearly 100\% humidity) (Barr \& Kuehne, 1971; Howarth, 1980), probably because of thinner exoskeletons and longer, attenuated appendages which result in higher rates of desiccation compared to surface taxa (Howarth, 1980). Consequently, troglobionts often occur in greater numbers in the deep cave zone because of higher and more stable humidity relative to other zones (Peck, 1976), and Barr \& Kuehne (1971) observed that troglobionts are largely absent from drier portions of Mammoth Cave in Kentucky under sandstone caprock and near entrances. However, caves represent only one component of a largely inaccessible but potentially extensive subterranean habitat that includes shallow subterranean habitats (SSH) (Juberthie et al., 1980), and Novak et al. (2012) suggest that there are two largely distinct groups of troglobionts; one specializing in $\mathrm{SSH}$, primarily within $10 \mathrm{~m}$ of the surface, and one in deeper cave habitats. This explains bimodal distributions of troglobiont abundance that peak near the entrance (the SSH fauna) and in the deep cave environment. Relative to troglobionts, the distribution of trogloxenes (occasional and temporary residents of caves) and troglophiles (non-obligate cave inhabitants) has been less well studied by biospeleologists. A number of studies have shown that the distribution and composition of guanobiont communities (comprised of troglobionts, troglophiles, and trogloxenes) is influenced by the size of guano piles, distance from the entrance (influencing guano quantity and quality and colonization), and guano pile microclimate (Ferriera \& Martins, 1998; ; Ferriera et al., 2000; Bahia \& Ferriera, 2005; Ferriera et al., 2007). Because of constraints imposed by environmental conditions, nutrient availability and competition with troglobionts, troglophiles typically decrease in abundance with increasing distances into a cave, although both troglobionts and troglophiles may occur in all parts of a cave system (Sendra et al., 2012).

Cave transition zones are influenced by both deep cave and surface climates and are characterized by seasonal movement of a temperature and/or high-humidity front that changes the extent and location of favorable habitat for troglobionts, troglophiles, and trogloxenes, consequently affecting interactions between these groups. While other studies have focused on species responses to nutrient quality and availability, to our knowledge, movement of species within caves in response to seasonally changing environmental conditions has not been assessed. Variability in temperature and troglobiont distribution has been studied, however, in the milieu souterrain superficiel (MSS): the interconnected subterranean spaces between soil and loose rock in scree and talus. Crouau-Roy et al. (1992) showed that both temperature and abundance of troglobionts showed strong seasonal cycles in an MSS in the Pyrenees. However, daily oscillations in temperature were not correlated to changes in troglobiont species richness in the MSS in a lava field in the Canary Islands (Pipan et al., 2010).

We expected that troglobionts and troglophiles (collectively referred to as cavernicoles) move within caves in response to the movement of a temperature variability and humidity front in the cave because of the physiological limitations discussed above. This behavior would be evident in a correlation between temporal changes in the longitudinal distribution of cavernicoles, and temporal changes in longitudinal patterns of cave temperature and humidity. In contrast, while it is likely that trogloxenes also display a preference for optimal environmental conditions, their ability to move within the subterranean environment in response to changing environmental conditions may be limited by some other aspect of the cave environment (e.g. distance from an entrance, darkness, low nutrient availability, competition with cavernicoles) because of a lack of troglomorphic adaptations. Consequently, we predicted that the presence of trogloxenes would decrease with increasing distance from the cave entrance as has previously been noted (Racoviță, 2006), although seasonal changes in the distribution of trogloxenes, corresponding with seasonal changes in the distribution of cavernicoles could indicate competition between these two ecological groups.

An understanding of community responses to incave climate seasonality (which is dependent on surface environmental conditions) is essential for: 1) understanding how these systems will respond to climate change and environmental variability, and 2) improving management of rare and vulnerable species. Ecosystems, such as caves, which are characterized by high levels of endemism, small, isolated patches of habitat, and species that are intolerant of climatic variation are especially vulnerable to rapidly changing climate. Consequently, the objectives of this research were to: 1 ) quantify the seasonal variability of in-cave climate from the entrance to the deep zone in Clough Cave in the Sierra Nevada, California, USA, and 2) document whether the distributions and the movements of both cavernicoles and trogloxenes are affected by incave climate variability.

\section{METHODS}

\section{Site description}

Clough Cave is a $140 \mathrm{~m}$ long cave formed in a marble cliff $40 \mathrm{~m}$ above the Kaweah River at an elevation of 1000 masl in Sequoia and Kings Canyon National Parks (SEKI) (Fig. 1). This region has a Mediterranean climate marked by extreme seasonality in temperature and humidity, with low temperatures $\left(<0^{\circ} \mathrm{C}\right)$ and high precipitation (700 $\mathrm{mm}$ ) in winter (November - April) and seasonal drought and high temperatures $\left(>40^{\circ} \mathrm{C}\right)$ in summer. 


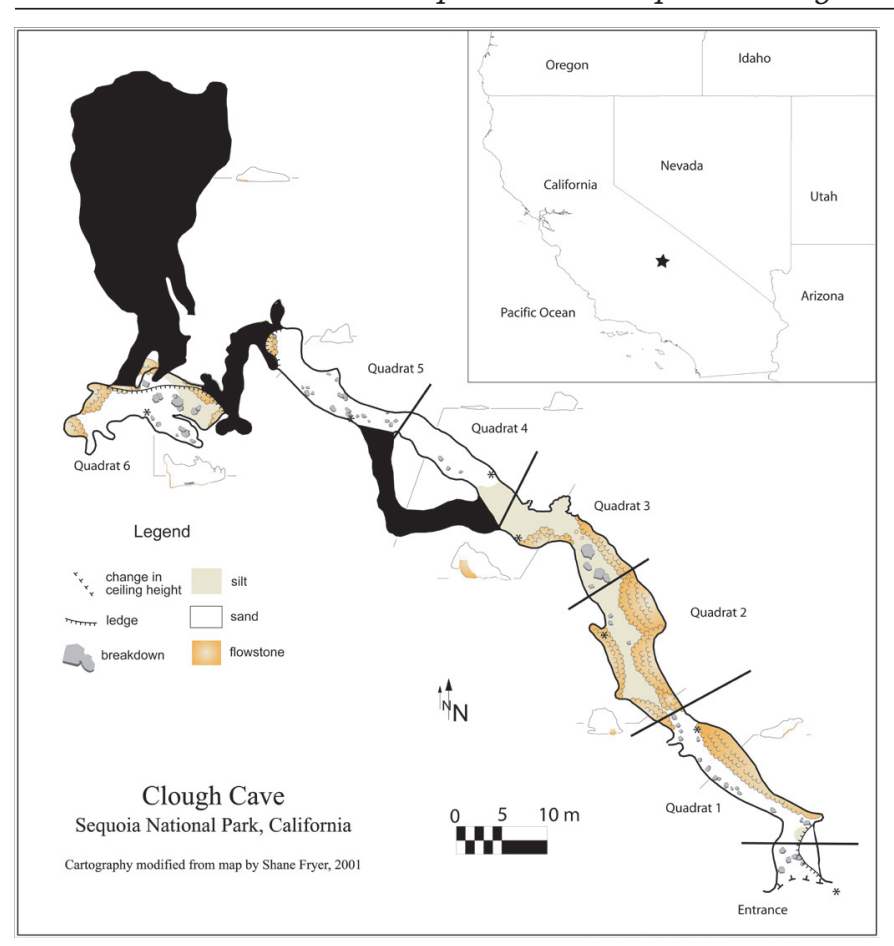

Fig. 1. Map of Clough Cave, California, USA (inset). Data logger locations are marked by asterisks. Blackened areas denote unsampled and unmonitored portions of the cave.

The main passage in Clough Cave is a highly decorated 2-4 $\mathrm{m}$ diameter abandoned stream meander passage (Fig. 1). A small crawlway side passage loop and an upper level passage at the back of the cave were not included in this study to reduce any potential effects that different passage morphologies might have on climate and species data. For this research, the main passage was divided into six approximately equal quadrats, beginning near the entrance and extending to the farthest reaches of the main passage (Fig. 1). Quadrats were assigned to either the entrance, transition, or deep cave zone based on physical characteristics (see results).

Clough Cave was chosen as a research site for multiple reasons. First, it is one of the most biologically diverse caves within SEKI, with over 50 documented invertebrate species (Krejca, 2006), including at least 10 cavernicoles. Secondly, the simple morphology of the cave provides an ideal study location with few confounding variables (e.g. multiple entrances, large sections of unfavorable habitat, etc.) that could obfuscate climatic effects on species distributions. Food sources for primary consumers appear to be evenly distributed throughout the cave, largely consisting of root mats from overlying trees and, to a lesser extent, vertebrate and invertebrate guano. Microhabitats such as breakdown, fractured bedrock, and wall habitat are also distributed evenly throughout the cave. Finally, as a small cave, it is similar to many caves world-wide, and results should be generalizable to other caves.

\section{Cave climate data collection}

In-cave temperature was recorded using Onset TidbiT $^{\circledR}$ temperature loggers in quadrats $1-5$, hidden from view to avoid theft. Additionally, Onset Hobo $^{\circledR}$ temperature and humidity loggers were placed in the entrance (before quadrat 1) and in quadrat 6
(Fig. 1). Data were collected at 15 minute intervals. Temperature data were converted into four variables: daily temperature average, daily temperature range, 2-week antecedent temperature average (prior to each biological inventory), and 2 -week antecedent temperature range. Temperature ranges were used rather than standard deviation because physiological functional constraints (including death) can occur at extreme temperature events, even if infrequent (Pörtner \& Ferrell, 2008). Furthermore, temperature range has been used as a measure of environmental stability for predicting species diversity (Owen et al., 1989).

A linear relationship between temperature and relative humidity was established using data collected at the cave entrance. Surface temperature is highly negatively correlated to relative humidity and we assume that a similar relationship exists within the transition zone, due to influence from the surface environment. However, because of a lack of instrumentation, humidity data were not collected in quadrats $1-5$, so we were unable to use humidity in statistical analyses.

\section{Biological inventories}

Between 10 May and 27 December 2010, five biologic inventories were conducted in Clough Cave. This time period spanned transitions from wet to dry seasons and back, and overlapped the period of highest variability in cave temperature and humidity. Each inventory consisted of 30 person-minutes of visual searches in each quadrat. Invertebrates were enumerated and identified to the lowest possible taxonomic level using picture keys derived from an existing species list for the cave (Krejca, 2006). To reduce potential researcher bias, inventories were conducted by the same people whenever possible. Although this method does not necessarily capture all species, it has been established as an acceptable monitoring method (Culver \& Sket, 2002) and is in line with conservation ethics of the United States National Park Service, minimizing disturbance to the ecosystem.

\section{Statistical analyses}

For each quadrat and sampling date, diversity (calculated using the Shannon-Weaver index, H'), abundance, and species richness (S) were calculated separately for cavernicoles and trogloxenes. Community-wide and species-specific responses were analyzed using multiple linear regression and canonical correspondence analysis, respectively. Cavernicole and trogloxene $\mathrm{H}^{\prime}$ were used as response variables, with cave quadrat, date, 2-week antecedent temperature average (ant T), and 2-week antecedent temperature range (antTr) used as predictor variables. Additionally, cavernicole and trogloxene abundances were used as predictors for trogloxene and cavernicole diversity, respectively, to assess competitive interactions. Although humidity is important, temperature was used as a proxy for humidity based on the relationship between temperature and humidity established from the data logger in the entrance of the cave.

Although $H^{\prime}$ is sensitive to small changes in community composition (i.e. the addition of one or a 
few individuals) when taxon richness and abundance is low, we felt that it was the most appropriate diversity measure available for several reasons. First, measures such as species richness and evenness fail to take into account relative abundances and species richness, respectively. Secondly, other diversity measures also suffer from the same sensitivity at low levels of taxon richness and abundance. Furthermore, H' downweights the relative importance of both very rare and very numerous species, and is affected more by relative abundances than absolute abundances (Sager \& Hasler, 1969), facilitating comparisons between ecological groups with potentially very different absolute abundances (e.g. cavernicoles and trogloxenes). Finally, species richness is a large component of the index (Sager \& Hasler, 1969) at the low levels of species richness $(\leq 10)$ commonly observed in caves.

Data were log or log-square-root transformed for normality, if necessary, and sampling date was centered to reduce potential multicolinearity. Quadrat was modeled as a random categorical variable using five dummy variables. Interactions among predictor variables were not included in any models. Akaike information criterion (AIC) analysis for finite sample sizes was then performed to select the most likely model. Cut-off for significance was set at $a=0.95$ and corresponding $\mathrm{p}$-values were calculated using the false discovery rate algorithm of Benjamini \& Hochberg (1995) and Narum (2006) to account for multiple hypothesis testing. Regressions and post hoc tests of differences among groups (Tukeys HSD) were run in $\mathrm{R}$ (R Development Core Team, 2012).

Canonical correspondence analysis (CCA) was used to assess species-specific cavernicole distributions in response to the measured environmental variables. Taxa that comprised less than $1 \%$ of the total abundance of cavernicoles collected on all sampling dates were removed from analysis. Additionally, abundance data were log transformed and the effect of rare species was down-weighted during ordination. Predictor variables were the same as those used in linear regressions and were partitioned into date, quadrat, and environmental effects. Significance of pure effects was determined using a Monte Carlo test (9999 permutations). CCA was performed using Canoco 4.5 (Braak \& Şmilauer, 2002).

\section{RESULTS}

\section{Climate data}

Climate data illustrate two major patterns: 1) with increasing distance into the cave, temperature changes and temperature range were increasingly attenuated and time-lagged relative to the surface (Fig. 2), and 2) changes in temperature and humidity were greatest at the transition between the wet (October to May) and dry (May to October) seasons.

Over the course of the study, daily temperature average at the entrance varied from $6.8^{\circ} \mathrm{C}$ to $22.52^{\circ} \mathrm{C}$. In contrast, quadrat 6 was relatively stable, with temperatures varying from $15.54^{\circ} \mathrm{C}$ to $17.21^{\circ} \mathrm{C}$ over the course of the study. Similarly, 2-week antecedent temperature averages

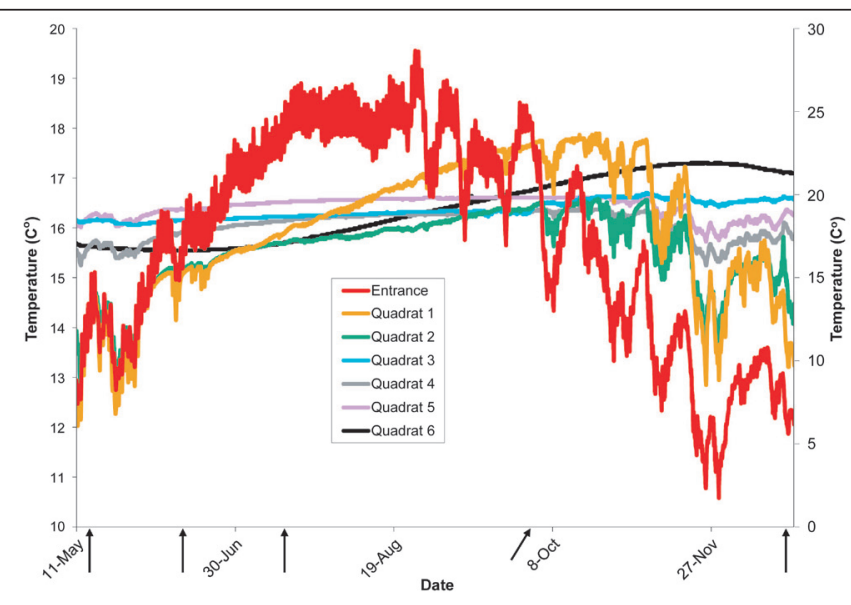

Fig. 2. 2010 temperature profiles for the entrance and each quadrat in Clough Cave. Left axis is for quadrats 1-6, and right axis is for entrance. Arrows note biologic inventory dates.

were more variable in the entrance $\left(8.03^{\circ} \mathrm{C}\right.$ to $21.27^{\circ}$ C) relative to the deep cave zone $\left(15.57^{\circ} \mathrm{C}\right.$ to $\left.17.19^{\circ} \mathrm{C}\right)$. Daily temperature range varied from $0.81^{\circ} \mathrm{C}$ to $11.9^{\circ} \mathrm{C}$ in the entrance and $0.02^{\circ} \mathrm{C}$ and $0.23^{\circ} \mathrm{C}$ in quadrat 6 . Two-week antecedent temperature range varied from $5.19^{\circ} \mathrm{C}$ to $11.9^{\circ} \mathrm{C}$ in the entrance zone and from $0.02^{\circ}$ $\mathrm{C}$ to $0.33^{\circ} \mathrm{C}$ in the deep cave zone (Fig. 3, Table 1). Twoweek antecedent temperature range was also reduced in quadrats 3-5, relative to the entrance and quadrats 1-2.

In the entrance and quadrat 1 , temperature peaked during late summer months (July - September). The highest temperatures in quadrats 2-5 occurred later (October - November), and peak temperature in quadrat 6 had a lag of 90 days relative to peak temperature near the surface. In the entrance and quadrats 1-2, 2-week antecedent temperature range peaked at the beginning (October) and end (May) of the wet season and was smallest during the peak of the dry season (July) (Fig. 3). In the entrance, humidity was low throughout the summer dry season and high (above 90\%) and relatively constant in the wet season. Daily temperature average and 2-week antecedent temperature average were highly correlated for all quadrants $\left(r^{2}=0.87\right.$ to $\left.>0.99\right)$. Daily temperature range and 2-week antecedent temperature range were also strongly correlated $\left(\mathrm{r}^{2}=0.65\right.$ to 0.81$)$ except in quadrant $6\left(\mathrm{r}^{2}=0.30\right)$, in which very stable conditions (discussed below) resulted in a lack of correlation. Consequently, only values of 2 -week antecedent temperature average and 2-week antecedent temperature range were used for regression analyses, and daily values are not discussed further.

In the entrance, humidity and temperature showed a strong, negative correlation $\left(r^{2}=0.88\right.$; Fig. 4). Humidity in quadrat 6 remained constant at over $100 \%$ over the course of the study, although this may be due, at least in part, to condensation forming on the logger. This nevertheless indicates a small humidity range that never dropped low enough to evaporate water that condensed on the logger. In addition to the humidity data collected in the entrance and quadrat 6 , we qualitatively observed a drying front in the sediments in the cave that moved progressively further into the cave during the dry season and then back towards the entrance during the wet season. This drying front 


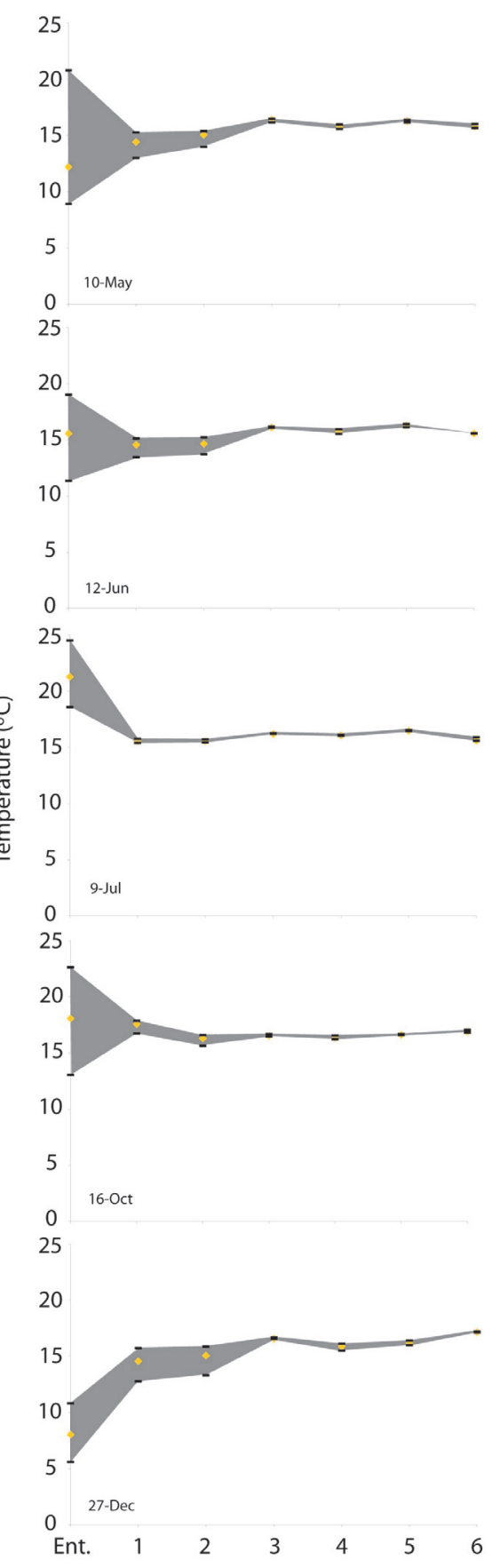

Fig. 3. Two-week antecedent average temperature and temperature range for the entrance (Ent.) and each quadrat (1-6) for each biological inventory date.

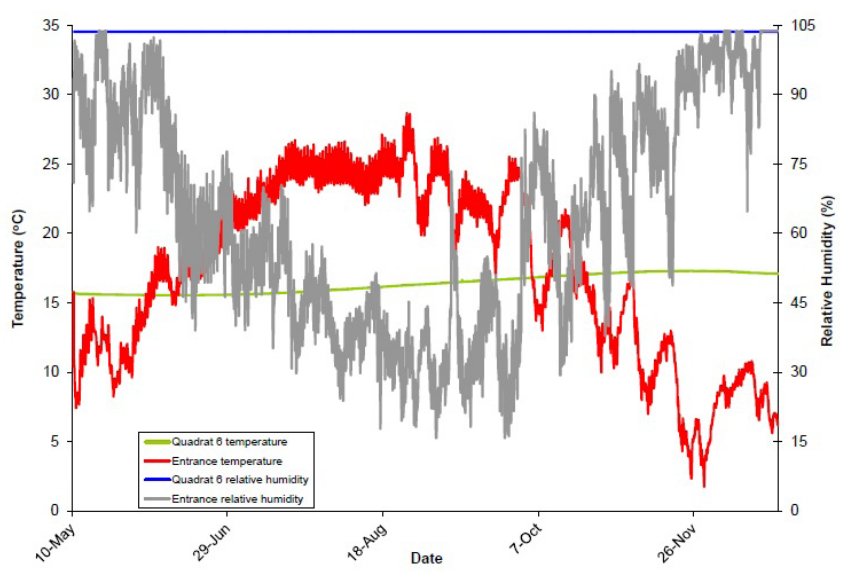

Fig. 4. Temperature and relative humidity plot for the entrance and quadrat 6. appears to be related to increased temperature in quadrats $1-3$, suggesting that temperature variability in these quadrats was high enough that humidity was periodically reduced to below saturation. These data suggest that temperature range may act as a proxy for humidity in the cave although there is not enough data to quantify this relationship.

Temperature data and proximity to the entrance were used to designate entrance, deep, or transitional zones. Quadrat 1 was assigned to the entrance zone because it is in the twilight zone and shows temperature and humidity fluctuations that are synchronous with the surface. Quadrats 2, 3, 4, and 5 were assigned to the transition zone because they are in the dark zone and, with the exception of quadrat 3, they show temperature profiles that suggest that they are influenced, at least seasonally, by surface temperatures. The lack of a similar pattern in quadrat 3 is probably due to its placement in an alcove with a stable microclimate than does not reflect the typical environmental pattern within the quadrat. Quadrat 6 was assigned to the deep zone because it is in the dark zone and displays relatively stable temperature profiles that are asynchronous with the surface.

\section{Faunal distribution patterns}

Flooding in the cave during the 27 December 2010 sampling event reduced the amount of searchable area by approximately $50 \%$. As a result, trogloxene richness, cavernicole richness, and abundances were all significantly lower for this sampling date (results of MANOVA, data not shown). Because data from this date were not representative of species' responses to temperature or humidity, they were excluded from analyses. Excluding the December data, 1117 individuals belonging to 31 taxa were recorded during biological inventories (Table 2, available online at http://dx.doi. org/10.5038/1827-806X.42.3.4). Seven taxa were represented by a single individual, and an additional 6 were represented by 2 or 3 individuals. Two taxa, the collembolan Tomocerus celsus and an unidentified psocopteran made up $68 \%$ of the total abundance. Chelicerates (spiders, mites, scorpions, and harvestmen) were an especially diverse component of the fauna, represented by 14 taxa comprising $19 \%$ of the total abundance (Table 2). The collembola Tomocerus celsus was recorded from every quadrat during every sampling event, with one exception. Other cavernicoles only rarely occurred outside of quadrats 5 or 6 (e.g. the spiders Yorima $s p$. and Usofila sp., and the scorpion Uroctonus mordax sequoiae). Conversely, several species of trogloxenes are largely restricted to the entrance zone (e.g. Titiotus sp., Nesticus silvestrii, Arcuphantes sp., and Cybeaus sp.). The two subspecies of scorpion, Uroctonus mordax mordax and $U$. mordax sequoiae appear to be restricted to the entrance and deep cave zone, respectively. Two species, the isopod Brackenridgia sp. and the harvestman Calicina cloughensis appeared to have a bimodal distribution, occurring most frequently in quadrats 1 and 6 , but rarely, if ever in the transition zone.

In general, trogloxenes and cavernicoles were present in similar numbers (average abundance per quadrat per sampling event $=19.7$ and 17.6 , respectively), although average trogloxene species richness (3.5 
Table 1. Two-week antecedent temperature, minimum temperature, maximum temperature and temperature range, species abundance, species richness and diversity $\left(\mathrm{H}^{\prime}\right)$ for cavernicoles and trogloxenes by sampling event and quadrat.

\begin{tabular}{|c|c|c|c|c|c|c|c|c|c|c|c|}
\hline \multirow[t]{2}{*}{ Date } & \multirow[t]{2}{*}{ Quadrat } & \multicolumn{4}{|c|}{2 -week Antecedent Temperature } & \multicolumn{3}{|c|}{ Cavernicoles } & \multicolumn{3}{|c|}{ Trogloxenes } \\
\hline & & Mean $\left({ }^{\circ} \mathrm{C}\right)$ & Maximum $\left({ }^{\circ} \mathrm{C}\right)$ & Minimum $\left({ }^{\circ} \mathrm{C}\right)$ & Range $\left({ }^{\circ} \mathrm{C}\right)$ & Abundance & Richness & $\mathrm{H}^{\prime}$ & Abundance & Richness & H \\
\hline \multirow{7}{*}{ 䎡 } & Entrance & 12.2 & 20.78 & 8.88 & 11.90 & & & & & & \\
\hline & 1 & 14.45 & 15.25 & 12.97 & 2.28 & 28 & 2 & 0.41 & 27 & 9 & 1.73 \\
\hline & 2 & 15.04 & 15.39 & 13.95 & 1.44 & 33 & 2 & 0.14 & 11 & 8 & 1.83 \\
\hline & 3 & 16.44 & 16.49 & 16.15 & 0.33 & 27 & 1 & 0.00 & 4 & 3 & 0.64 \\
\hline & 4 & 15.80 & 15.96 & 15.56 & 0.40 & 18 & 2 & 0.21 & 6 & 3 & 0.50 \\
\hline & 5 & 16.30 & 16.39 & 16.15 & 0.24 & 36 & 1 & 0.00 & 6 & 4 & 0.95 \\
\hline & 6 & 15.81 & 15.99 & 15.66 & 0.33 & 35 & 6 & 1.50 & 3 & 4 & 0.69 \\
\hline \multirow{7}{*}{ 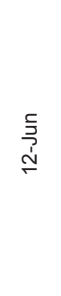 } & Entrance & 15.56 & 19.02 & 11.36 & 7.66 & & & & & & \\
\hline & 1 & 14.57 & 15.10 & 13.43 & 1.68 & 7 & 2 & 0.41 & 15 & 6 & 1.63 \\
\hline & 2 & 14.66 & 15.20 & 13.71 & 1.48 & 5 & 1 & 0.00 & 6 & 3 & 1.08 \\
\hline & 3 & 16.10 & 16.15 & 16.06 & 0.09 & 19 & 2 & 0.21 & 6 & 1 & 0.00 \\
\hline & 4 & 15.74 & 15.92 & 15.51 & 0.41 & 8 & 1 & 0.00 & 4 & 2 & 0.69 \\
\hline & 5 & 16.27 & 16.37 & 16.13 & 0.24 & 8 & 4 & 1.07 & 61 & 2 & 0.08 \\
\hline & 6 & 15.55 & 15.57 & 15.54 & 0.02 & 23 & 5 & 1.48 & 5 & 4 & 0.64 \\
\hline \multirow{7}{*}{ 勇 } & Entrance & 21.27 & 24.52 & 18.57 & 5.95 & & & & & & \\
\hline & 1 & 15.57 & 15.75 & 15.39 & 0.36 & 30 & 4 & 1.11 & 18 & 7 & 1.49 \\
\hline & 2 & 15.56 & 15.68 & 15.44 & 0.24 & 7 & 3 & 0.80 & 10 & 6 & 1.46 \\
\hline & 3 & 16.19 & 16.23 & 16.18 & 0.05 & 13 & 3 & 0.54 & 5 & 3 & 0.56 \\
\hline & 4 & 16.06 & 16.13 & 16.01 & 0.12 & 3 & 1 & 0.00 & 26 & 5 & 0.63 \\
\hline & 5 & 16.47 & 16.51 & 16.44 & 0.07 & 3 & 2 & 0.64 & 36 & 2 & 0.21 \\
\hline & 6 & 15.60 & 15.90 & 15.57 & 0.33 & 32 & 5 & 1.11 & 8 & 4 & 1.15 \\
\hline \multirow{7}{*}{$\begin{array}{l}\overrightarrow{\mathrm{U}} \\
\stackrel{0}{0} \\
\stackrel{\sigma}{0}\end{array}$} & Entrance & 18.04 & 22.62 & 13.00 & 9.62 & & & & & & \\
\hline & 1 & 17.56 & 17.82 & 16.68 & 1.14 & 16 & 3 & 0.86 & 45 & 7 & 1.39 \\
\hline & 2 & 16.31 & 16.56 & 15.63 & 0.93 & 49 & 2 & 0.10 & 6 & 3 & 0.69 \\
\hline & 3 & 16.50 & 16.63 & 16.44 & 0.19 & 47 & 2 & 0.10 & 16 & 5 & 1.10 \\
\hline & 4 & 16.34 & 16.53 & 16.20 & 0.33 & 11 & 2 & 0.66 & 205 & 4 & 0.03 \\
\hline & 5 & 16.61 & 16.65 & 16.56 & 0.10 & 1 & 1 & 0.00 & 23 & 3 & 0.41 \\
\hline & 6 & 16.89 & 16.99 & 16.78 & 0.21 & 43 & 5 & 1.30 & 5 & 1 & 0.45 \\
\hline \multirow{7}{*}{$\begin{array}{l}0 \\
\stackrel{0}{0} \\
\text { స }\end{array}$} & Entrance & 8.03 & 10.79 & 5.60 & 5.19 & & & & & & \\
\hline & 1 & 14.55 & 15.70 & 12.73 & 2.97 & 0 & 0 & NA & 13 & 4 & 1.27 \\
\hline & 2 & 15.05 & 15.82 & 13.31 & 2.51 & 0 & 0 & NA & 1 & 1 & 0.00 \\
\hline & 3 & 16.58 & 16.63 & 16.51 & 0.12 & 9 & 1 & 0.00 & 1 & 1 & 0.00 \\
\hline & 4 & 15.87 & 16.11 & 15.46 & 0.65 & 0 & 0 & NA & 18 & 1 & 0.00 \\
\hline & 5 & 16.19 & 16.37 & 15.96 & 0.41 & 1 & 1 & 0.00 & 0 & 0 & NA \\
\hline & 6 & 17.14 & 17.19 & 17.09 & 0.09 & 15 & 3 & 0.97 & 0 & 0 & NA \\
\hline
\end{tabular}

spp.) was slightly higher than average cavernicole species richness (2.2 spp.). Variability among samples was also greater for trogloxenes (standard deviation of abundance $=37.7$ versus 15.1 for cavernicoles) (Table 1 ). For both trogloxenes and cavernicoles, S and H' were highly correlated $\left(\mathrm{r}^{2}=0.79\right.$ and 0.88 , respectively), although no correlation between abundance and $\mathrm{H}^{\prime}$ was observed $\left(\mathrm{r}^{2}=0.09\right.$ and 0.02 , respectively). Trogloxene diversity was typically highest in the entrance zone (quadrat 1), and to a lesser extent, in the deep cave zone, whereas cavernicoles diversity was typically highest in the deep cave zone and, to a lesser extent, in the entrance zone. Transition zone quadrats had lower overall diversity and abundance values than quadrats near the entrance or back of the cave, although this pattern was more pronounced in cavernicoles than in trogloxenes. Cavernicole diversity and species richness appear to peak in the summer dry season for quadrats 1-3. This temporal pattern is not apparent in quadrats 4-6 (Table 1). Trogloxene diversity and species richness appear to decrease over the course of the summer dry season, although the pattern is not apparent in quadrats 3 and 6 (Table 1).

\section{Regression analysis}

To test for a relationship between diversity $\left(\mathrm{H}^{\prime}\right)$ and climatic variables, 9 linear regression models containing between 1 and 5 predictor variables were run separately for cavernicoles and trogloxenes (Table 3). For cavernicoles, AIC suggested that, of the evaluated models, the full model (quadrat + date +2 -week antecedent temperature average +2 -week antecedent temperature range $+\log$ (trogloxenes abundance)) had a $57 \%$ chance of being the most likely model and was 2.0 times more likely than the next best model, although the quadrat $+\log$ (trogloxenes abundance) model was a competing model, with a $29 \%$ chance of being most likely. The full model explained $76 \%$ of the variance in diversity but included three non-significant parameters: intercept $\mathrm{p}=0.09$, quadrat $2 \mathrm{p}=0.58$, and 2 -week antecedent temperature average $\mathrm{p}=0.06$. The quadrat $+\log$ (trogloxene abundance) model explained 
Table 3. Alternative linear regression models assessed using Akaike Information Criterion corrected for finite sample sizes (AICc). Only predictor variables are listed. The response variable is Shannon's diversity index: $H^{\prime}$ from Table $1 . k=$ the number of parameters included, $\Delta=\mathrm{AICc}-\mathrm{AlCc}_{\min }$. The most likely model (or competing models) are in bold. ant $\mathrm{T}=2$ week antecedent temperature average $\left({ }^{\circ} \mathrm{C}\right)$, ant $T r=2$ week antecedent temperature range, Abundance $=$ trogloxene abundance.

\begin{tabular}{|c|c|c|c|c|c|c|c|c|c|}
\hline Model & $\mathbf{r}^{2}$ & $\mathbf{F}$ & df & $\mathbf{p}$ & $\mathrm{k}$ & AIC & AICc & $\Delta$ & AICc weights \\
\hline \multicolumn{10}{|c|}{ Cavenicoles, all sites } \\
\hline quadrat+date+ant $T+a n t T r+\log ($ trogloxene abundance) & 0.76 & 9.00 & $9 \& 14$ & 0.00 & 11.00 & 11.13 & 25.79 & 0.00 & 0.57 \\
\hline quadrat+date+ant $T+\log ($ trogloxene abundance) & 0.65 & 6.26 & $8 \& 15$ & 0.00 & 10.00 & 19.86 & 31.44 & 5.64 & 0.03 \\
\hline date+ant $T+\log ($ trogloxene abundance) & -0.14 & 0.06 & $3 \& 20$ & 0.98 & 5.00 & 44.88 & 47.38 & 21.59 & 0.00 \\
\hline ant T+antTr & -0.02 & 0.83 & $2 \& 21$ & 0.45 & 4.00 & 41.26 & 42.86 & 17.06 & 0.00 \\
\hline antT & -0.04 & 0.16 & $1 \& 22$ & 0.69 & 3.00 & 40.91 & 41.84 & 16.04 & 0.00 \\
\hline quadrat+log(trogloxene abundance) & 0.63 & 7.41 & $6 \& 17$ & 0.00 & 8.00 & 20.24 & 27.10 & 1.30 & 0.29 \\
\hline quadrat & 0.55 & 6.62 & $5 \& 18$ & 0.00 & 7.00 & 24.05 & 29.14 & 3.35 & 0.11 \\
\hline date+log(trogloxene abundance) & -0.09 & 0.04 & $2 \& 21$ & 0.96 & 4.00 & 43.00 & 44.60 & 18.80 & 0.00 \\
\hline log(trogloxene abundance) & -0.05 & 0.05 & $1 \& 22$ & 0.83 & 3.00 & 41.03 & 41.96 & 16.16 & 0.00 \\
\hline \multicolumn{10}{|c|}{ Trogloxenes, all sites } \\
\hline quadrat+date+ant $T+a n t T r+\log ($ cavernicole abundance) & 0.55 & 4.07 & $9 \& 14$ & 0.01 & 11.00 & 28.98 & 43.64 & 11.97 & 0.00 \\
\hline quadrat+date+ant $T+\log$ (cavernicole abundance) & 0.55 & 4.45 & $8 \& 15$ & 0.01 & 10.00 & 28.66 & 40.24 & 8.56 & 0.01 \\
\hline date+ant $T+\log ($ cavernicole abundance) & 0.29 & 4.11 & $3 \& 20$ & 0.02 & 5.00 & 36.31 & 38.81 & 7.14 & 0.02 \\
\hline ant $T+$ ant $T r$ & 0.32 & 6.31 & $2 \& 21$ & 0.01 & 4.00 & 34.53 & 36.13 & 4.46 & 0.07 \\
\hline antT & 0.25 & 8.59 & $1 \& 22$ & 0.01 & 3.00 & 35.92 & 36.85 & 5.17 & 0.05 \\
\hline quadrat+log(cavernicole abundance) & 0.54 & 5.51 & $6 \& 17$ & 0.00 & 8.00 & 27.90 & 34.76 & 3.08 & 0.15 \\
\hline quadrat & 0.55 & 6.71 & $5 \& 18$ & 0.00 & 7.00 & 26.59 & 31.68 & 0.00 & 0.69 \\
\hline date+log(cavernicole abundance) & 0.01 & 1.13 & $2 \& 21$ & 0.34 & 4.00 & 43.37 & 44.97 & 13.29 & 0.00 \\
\hline log(cavernicole abundance) & 0.03 & 1.59 & $1 \& 22$ & 0.22 & 3.00 & 42.16 & 43.08 & 11.41 & 0.00 \\
\hline \multicolumn{10}{|c|}{ Cavernicoles, transition zone } \\
\hline quadrat+date+ant $T+a n t T r+\log ($ trogloxene abundance) & 0.36 & 2.20 & $7 \& 8$ & 0.15 & 9.00 & 11.21 & 20.21 & 8.82 & 0.01 \\
\hline quadrat+date+ant $T+\log ($ (trogloxene abundance) & 0.11 & 1.32 & $6 \& 9$ & 0.34 & 8.00 & 16.33 & 23.18 & 11.79 & 0.00 \\
\hline date+ant $T+\log$ (trogloxene abundance) & 0.21 & 2.32 & $3 \& 12$ & 0.13 & 5.00 & 13.08 & 15.58 & 4.19 & 0.07 \\
\hline ant $T+$ ant $T r$ & 0.02 & 1.13 & $2 \& 13$ & 0.35 & 4.00 & 15.84 & 17.44 & 6.05 & 0.03 \\
\hline antT & -0.06 & 0.10 & $1 \& 14$ & 0.76 & 3.00 & 16.29 & 17.21 & 5.82 & 0.03 \\
\hline quadrat+log(trogloxene abundance) & 0.14 & 1.61 & $4 \& 11$ & 0.24 & 6.00 & 15.04 & 18.70 & 7.31 & 0.01 \\
\hline quadrat & -0.16 & 0.30 & $3 \& 12$ & 0.83 & 5.00 & 19.26 & 21.76 & 10.37 & 0.00 \\
\hline date+log(trogloxene abundance) & 0.27 & 3.77 & $2 \& 13$ & 0.05 & 4.00 & 11.08 & 12.68 & 1.29 & 0.29 \\
\hline log(trogloxene abundance) & 0.26 & 6.29 & $1 \& 14$ & 0.03 & 3.00 & 10.47 & 11.39 & 0.00 & 0.56 \\
\hline \multicolumn{10}{|c|}{ Trogloxenes, transition zone } \\
\hline quadrat+date+ant $T+a n t T r+\log ($ cavernicole abundance) & 0.28 & 1.84 & $7 \& 8$ & 0.21 & 9.00 & 25.60 & 34.60 & 12.60 & 0.00 \\
\hline quadrat+date+ant $T+\log$ (cavernicole abundance) & 0.25 & 1.81 & $6 \& 9$ & 0.20 & 8.00 & 26.28 & 33.13 & 11.14 & 0.00 \\
\hline date+ant $T+\log$ (cavernicole abundance) & 0.31 & 3.21 & $3 \& 12$ & 0.06 & 5.00 & 23.54 & 26.04 & 4.04 & 0.07 \\
\hline antT+antTr & 0.40 & 6.08 & $2 \& 13$ & 0.01 & 4.00 & 20.40 & 22.00 & 0.00 & 0.51 \\
\hline ant & 0.28 & 6.96 & $1 \& 14$ & 0.02 & 3.00 & 22.51 & 23.43 & 1.43 & 025 \\
\hline quadrat+log(cavernicole abundance) & 0.32 & 2.78 & $4 \& 11$ & 0.08 & 6.00 & 23.78 & 27.43 & 5.43 & 0.03 \\
\hline quadrat & 0.35 & 3.71 & $3 \& 12$ & 0.04 & 5.00 & 22.45 & 24.95 & 2.96 & 0.12 \\
\hline date+log(cavernicole abundance) & -0.02 & 0.85 & $2 \& 13$ & 0.45 & 4.00 & 29.00 & 30.60 & 8.60 & 0.01 \\
\hline log(cavernicole abundance) & 0.02 & 1.35 & $1 \& 14$ & 0.27 & 3.00 & 27.49 & 28.41 & 6.42 & 0.02 \\
\hline
\end{tabular}

$63 \%$ of the variability. For trogloxenes, AIC suggested that of the evaluated models, the quadrat model had a $69 \%$ chance of being the most likely, was 4.6 times more likely than the next best model, and explained $55 \%$ of the variance in diversity.

For both cavernicoles and trogloxenes, $\mathrm{H}^{\prime}$ was significantly affected by quadrat $(p=0.04 \& 0.01$, respectively) and, contrary to our expectations, cavernicole H' was positively correlated with trogloxene abundance $(p=0.04)$. Regressions predict diversity equally well for all sampling dates and quadrats (Fig. 5ad). For cavernicoles, Tukeys HSD post hoc test revealed that quadrat 6 had significantly higher H' values than quadrats $2-5(\mathrm{p} \leq 0.05)$, but not quadrat $1(\mathrm{p}=0.132)$. For trogloxenes, Tukeys HSD post hoc test revealed that quadrat 1 had significantly higher diversity than all other quadrats, with the exception of quadrat 2. Quadrat 2 also had significantly higher diversity than the transition quadrat 5 .

To investigate changes in diversity within the transition zone, linear regressions were run for cavernicoles and trogloxenes in quadrats 2-5 (Table 3). For cavernicoles in quadrats $2-5$, AIC suggested that of the evaluated models, the date $+\log$ (trogloxene abundance) model and the $\log$ (trogloxene abundance) model were competing, having $29 \%$ and $56 \%$ chances of being the most likely 
models, respectively. The log (trogloxene abundance) model was 1.9 times more likely than the date + log (trogloxene abundance) model. The two models explained $26 \%$ and $27 \%$ of the variance in diversity, respectively, although in the date $+\log$ (trogloxene abundance) model, the coefficient for date was not significant $(p=0.298)$. For trogloxenes in quadrats 2-5, AIC suggested that of the evaluated models, the 2 -week antecedent temperature
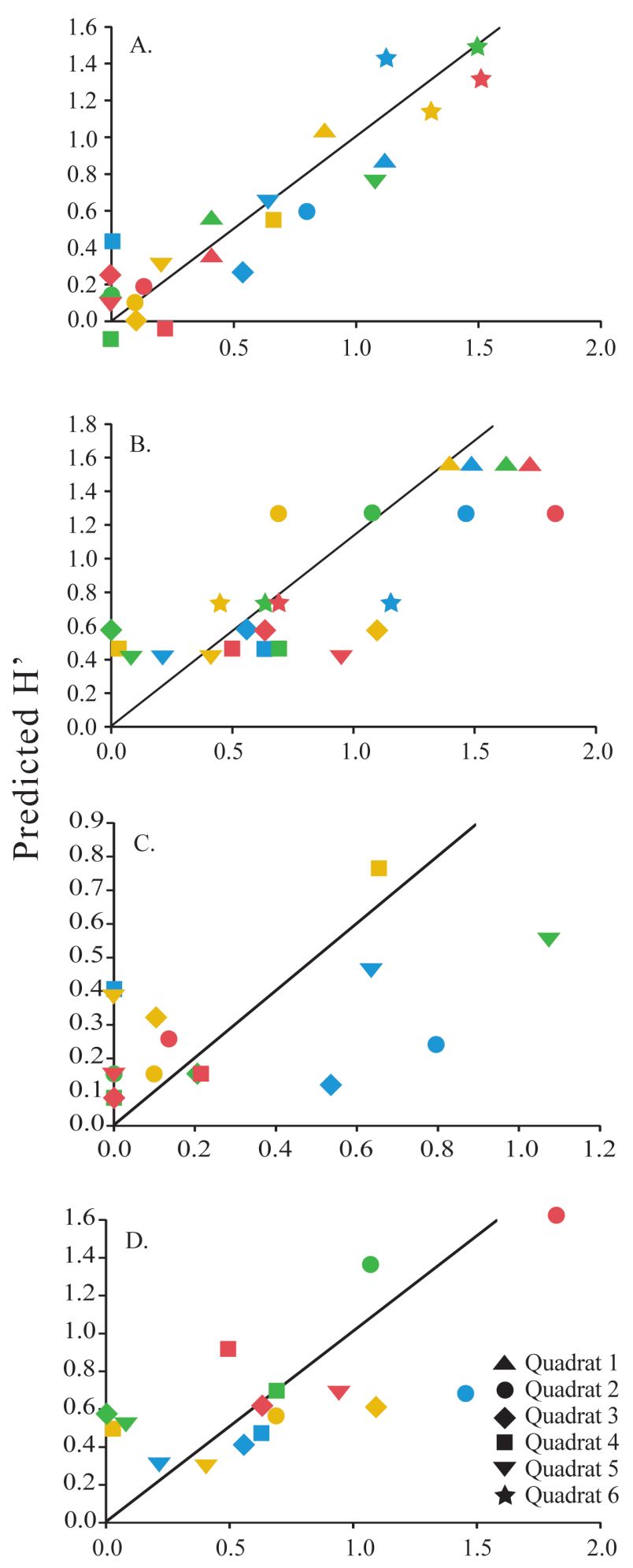

Observed H'

Fig. 5. Observed versus predicted diversity $\left(H^{\prime}\right)$. May sampling events are red, June sampling events are green, July sampling events are blue, and August sampling events are orange. Trendlines pass through the origin and have a slope of 1 . a) cavernicoles; b) trogloxenes; c) cavernicoles in quadrats 2-5; d) trogloxenes in quadrats 2-5. average +2 -week antecedent temperature range model and the 2 -week antecedent temperature average model were competing, having $51 \%$ and $25 \%$ chances of being the most likely models, respectively. The 2-week antecedent temperature average +2 -week antecedent temperature range model was 2.1 times more likely than the 2-week antecedent temperature average model. The two models explained $40 \%$ and $28 \%$ of variance in diversity, respectively. Tukeys HSD post hoc test did not reveal any significant pairwise differences in trogloxene $\mathrm{H}^{\prime}$ among quadrats. As in the models evaluating all quadrats, cavernicole H' was positively correlated with trogloxene abundance in the transition zone models. Unlike in the all quadrats models, however, trogloxene $\mathrm{H}^{\prime}$ in the transition zone was positively correlated with 2-week antecedent temperature average.

\section{Canonical correspondence analysis of cavernicoles and environmental variables}

In a CCA of species distributions and environmental variables, $58.7 \%$ of variance in cavernicole distribution was explained by all canonical axes $(F=1.554, p=0.0121)$ (Fig. 6). The first four canonical axes alone explained $49.7 \%$ of variance in cavernicole distribution. Explained variance was partitioned into quadrat, environment, date, and interaction effects. Quadrat alone explained $35 \%$ of variance in cavernicole distribution $(\mathrm{F}=2.058$, $\mathrm{p}=0.003)$, date alone explained $11.5 \% \quad(\mathrm{~F}=0.113$, $\mathrm{p}=0.344$ ), and environment (temperature variables and trogloxene abundance) explained $11.1 \%(\mathrm{~F}=1.077$, $\mathrm{p}=0.378$ ). The remaining $1.1 \%$ was attributable

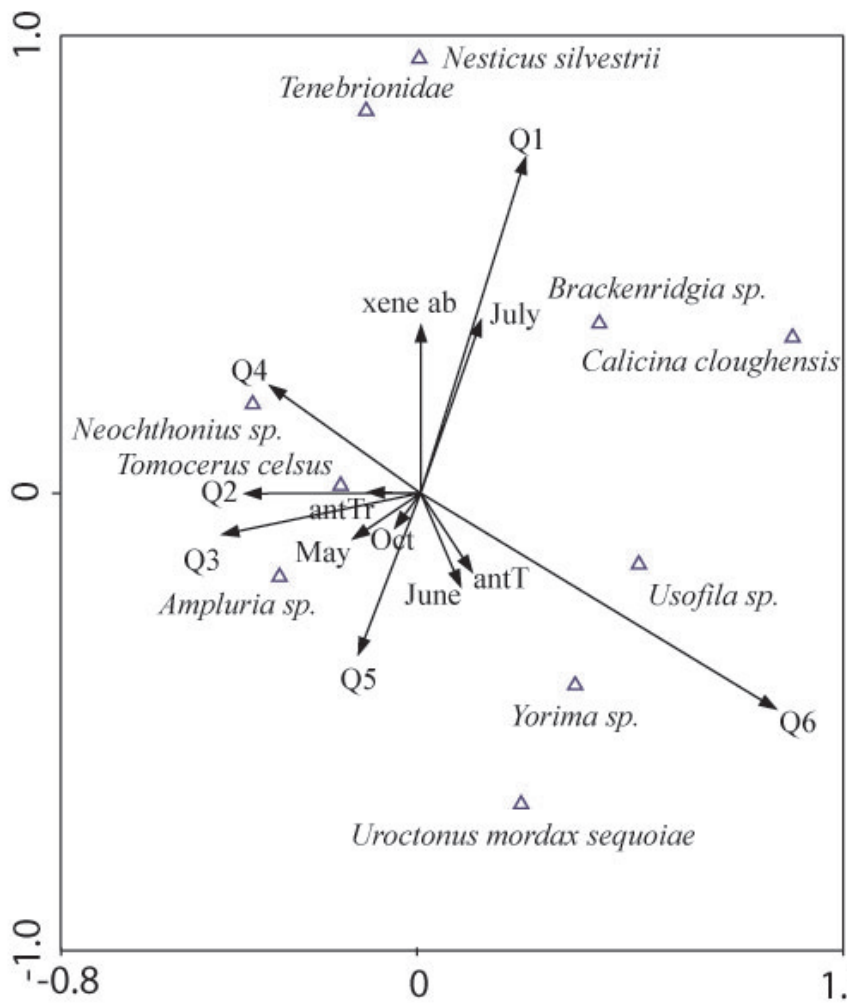

Fig. 6. Ordination diagram of cavernicole distribution data. Rare species are excluded. Eigenvectors (lines) show 13 environmental variables. Q1 - 6 = quadrats 1 - 6. antT $=2$ week antecedent temperature, ant $\mathrm{Tr}=2$ week antecedent temperature range, $x$ ene $\mathrm{ab}=$ abundance of trogloxenes. Canonical axes 1 and 2 explain $36 \%$ of speciesenvironmental correlation. Eigenvalues are 0.229 and 0.148 for CC1 and CC2, respectively. 
to secondary and tertiary (interaction) effects. For five cavernicoles (Ampluria sp., Tomocerus celsus, Brackenridgia sp., Usofila sp., and Yorima sp.), over 50\% of variance in abundance was explained by the first four canonical axes. Axes primarily explained differences in community structure due to quadrat effect. However, weaker gradients explained by trogloxene abundance and date were also illustrated.

\section{DISCUSSION}

Caves and other subterranean habitats are not stable environments as is often assumed, but exhibit seasonal fluctuations in temperature and humidity that reflect a delayed response to changing climate on the surface. High frequency, continuous temperature monitoring showed that environmental conditions are most variable in the entrance and, with increasing distance into the cave, become increasingly stable and temporally lagged relative to surface conditions.

During the winter and spring wet season (beginning in late November), climate in the entrance of Clough Cave is influenced by surface conditions. Cool and humid surface air moves into the entrance and nearsurface quadrats, resulting in decreased temperature, increased temperature range, and higher humidity (Fig. 4). These effects are attenuated and lagged in the deep cave, but temperatures begin to gradually decrease in deep-cave quadrats at the same time. At the end of the wet season (late May - early June) airflow direction reverses, and cave air begins to blow from the deep zone toward the entrance, raising temperatures in the cave. This, combined with more stable surface climate, leads to smaller temperature ranges (Fig. 3), although hot and dry conditions on the surface cause drying in the cave entrance.

As has been previously noted (Barr \& Kuene, 1971; Peck, 1976; Howarth, 1980), troglobionts and troglophiles are, in many cases, restricted to areas with the most stable temperature and humidity levels or, at least, to areas where temperature stability and humidity remain above some threshold. Consequently, cave-wide seasonal changes in temperature and humidity could exert major influences on cavernicoles distribution. As previously stated, humidity was not directly measured in this study, but preliminary observations suggest a negative correlation between temperature and humidity in Clough Cave.

Cavernicole distribution patterns exhibited significant cave-wide spatial and temporal trends but did not significantly respond to 2 -week antecedent temperature average. Several mechanisms may explain the lack of a relationship between cavernicole diversity and temperature: 1) Vagility is so low for some species that despite intermittent periods of environmentally favorable conditions, unfavorable periods are too frequent in the transition zone to allow for colonization and persistence. 2) Favorable micro-habitats (e.g. under stones, mesovoids, etc.) were more prevalent in some quadrats, allowing the persistence of animals year-round. This could explain the higher diversity seen in quadrats 1 and 6, although no a priori physical differences among quadrats were observed. 3) Temperature and relative humidity stayed within tolerance ranges for the species detected during our sampling events. Troglobionts are often regarded as stenothermic and stenohygrobic although temperature and relative humidity tolerances have been determined for only a few species. Howarth (1980) reported 50\% mortality in Hawaiian lavatube lycosid spiderlings after 15.4 days following exposure to $90 \%$ relative humidity. Bull and Mitchell (1972) reported less than 50\% survivorship after $12 \mathrm{hr}$ exposure to $50 \%$ relative humidity in a species of Texas cave millipede. Lencioni et al. (2010) reported lower lethal temperatures well below $0^{\circ} \mathrm{C}$ for two species of troglobitic leptodirin beetles from Italy although the beetles were collected from caves with mean temperatures of 9.3 and $9.8^{\circ} \mathrm{C}$.

The lack of correlation between trogloxene abundance and date and temperature supports our hypothesis that at least some trogloxenes are likely limited by other physiological constraints (e.g. dependence on sight, dispersal ability, etc.) and may thus be unable to migrate and/or persist with increasing distance into the cave. This is also supported by higher trogloxene diversity in quadrat 1 .

Species did exhibit significant responses to temperature within the transition zone, where trogloxene $H^{\prime}$ varied among transition zone quadrats due, in part, to differences in temperature among quadrats. Specifically, trogloxene diversity was inversely related to 2-week antecedent temperature average. The highest trogloxene $H^{\prime}$ values from transition zone quadrats occurred in June and July, when the temperature was most stable and the atmosphere in the cave was dominated by cooler, more humid and thermally stable air from the deep cave zone.

Differences in assemblage structure among quadrats were largely due to differences between the distributional patterns of cavernicoles and trogloxenes. These differences are likely due to environmental variability within the cave. For trogloxenes, diversity was highest in the entrance, and for cavernicoles, diversity was highest in the entrance and in the deepest, most environmentally stable quadrat. The non-significant difference between cavernicole diversity in quadrat 1 and quadrat 6 may be due to a lack of power in our statistical analyses due to small sampling size. For every sampling event except July, richness and diversity of cavernicoles was higher in quadrat 6 , and additional sampling may show that this trend is significant. Furthermore, several taxa analyzed in this study are currently undescribed and their ecology is unknown. Therefore, we conservatively grouped troglophiles and troglobionts into a single ecological category (cavernicoles). Better ecological characterization of these species is needed to identify potential differences between the responses of troglophiles and troglobionts to environmental variability in the Sierra Nevada. Peaks in cavernicole diversity in the entrance and deep cave zones parallel the observations of Novak et al. (2012) and may reflect distinct troglobiont communities (e.g. shallow epikarst, SSH, and MSS communities versus deep cave communities). In Clough Cave, diversity and 
richness were lowest in the transition zone. This observation is in contrast to other systems in which diversity of the ecotone between terrestrial (dominated by surface taxa) and hypogean habitats (dominated by troglobiont taxa) was higher than in adjoining habitats (Prous et al., 2004). Correlation between H' and species richness and lack of correlation between diversity and abundance suggest that changes in $\mathrm{H}^{\prime}$ reflect changes in species richness and species relative abundances, but not in absolute abundances.

It is important to note that additional cave-wide changes in community structure not related to temperature and humidity were also observed. Specifically, the December sampling event had significantly lower diversity, richness, and abundance values for cavernicoles and trogloxenes. This inventory occurred after a record precipitation event led to large portions of all quadrats being flooded. This suggests that in addition to cyclic environmental variability, infrequent disturbance events related to surface environmental conditions can have significant impacts on the distribution of species within subsurface habitats. Changes in the distributional patterns of subterranean species (including extirpation) in response to both natural and anthropogenic changes in surface conditions have been noted in other systems, but mostly for aquatic species (Culver et al., 1992; Dole-Olivier \& Marmonier, 1992; Culver \& Pipan, 2009 and references therein).

The community-wide responses to spatial and temporal conditions discussed above do not apply to all species found within the cave, and some speciesspecific patterns are worth noting. Distributional patterns of species were non-random and responses to environmental conditions varied among species, possibly obscuring community scale patterns. For example, the ubiquitous collembola Tomocerus celsus appears to occupy a larger ecological niche than other cavernicoles: appearing in all quadrats whereas most other cavernicoles were found almost exclusively in quadrats 1,5 or 6 . The distributions of the predatory, cavernicolous spiders Yorima $s p$. and Usofila $s p$. that occur primarily in the deep cave zone, may be limited by competition with the trogloxene spiders Titiotus sp., Nesticus silvestrii, Arcuphantes sp., and Cybeaus $s p$. that occur near the cave entrance. Yorima $s p$. and Usofila sp. are hunting and web-building spiders, respectively, and these different predation strategies may allow them to co-exist in the deep cave zone where animal abundances are generally lower. Competitive exclusion may also limit the distribution of the two subspecies of scorpion, Uroctonus mordax mordax and $U$. mordax sequoiae which are a trogloxene (occurring in the near-entrance quadrats) and a cavernicole (occurring in the deep-cave quadrats), respectively. Reasons for the apparently bimodal distribution of the isopod Brackenridgia sp. and the harvestman Calicina cloughensis are unclear.

Factors other than meteorological conditions also influence the distribution of cavernicoles and trogloxenes, but these confounding factors are minimized in Clough Cave. Although not measured, nutrient availability and substrate appear to be relatively evenly distributed among quadrats, suggesting that these variables play a minor role in controlling species distribution in Clough Cave. However, the positive correlation between cavernicole richness and trogloxene abundance may suggest that both groups are responding to some unmeasured variable. The relation also suggests that competition between these groups is not controlling distributions

\section{CONCLUSIONS}

Trogloxene diversity is highest near the entrance of caves, likely because of physiological limitations. Conversely, in Clough Cave, cavernicole diversity was highest in quadrat 6 where humidity and temperature were most stable and humidity is highest. Diversity was always low for cavernicoles and trogloxenes in the transition zone, even though climate in the transition zone was periodically similar to both entrance and deep cave conditions. This suggests that conditions within the transition zone are unfavorable for both groups because of environmental variability (cavernicoles), distance from the entrance (trogloxenes), or some unmeasured variable.

Climate change models for the Sierra Nevada predict an increase in temperature and minimal change in precipitation for the region (Cayan et al., 2008). Increased surface temperature is likely to cause an increase in the temperature difference between the deep cave and surface environments, increasing the length and variability of the transition zone. This in turn may further separate trogloxene- and cavernicoles-dominated communities and potentially reduce allochthonous resources in the deep cave environment. Because many cave adapted species are likely stenothermic and stenohygrobic, they are potentially susceptible to both seasonal and long-term climate changes that would, at least periodically, increase temperature variability and decrease humidity in cave entrances and transitions zones in temperate regions.

Our understanding of subterranean community responses to climate variability is incomplete. High frequency, long-term monitoring of community structure and inclusion of humidity data from throughout the cave is needed to detect changes that may not have been detected in this study. Additional studies should focus on 1) microhabitat (i.e. under stones, small alcoves, areas affected by drips) that may sustain favorable microclimates for stenohygrobic species, and 2) how cave morphology affects temperature, relative humidity, airflow patterns and the size of the transition zone. Furthermore, trogloxenes and troglophiles deserve more attention as they are an important component of the ecological community of caves. Finally, the basic ecology of all cave inhabitants needs to be better understood in order to predict both species-specific and community wide responses to environmental variability.

\section{ACKNOWLEDGEMENTS}

We would like to acknowledge the U.S. National Park Service for allowing access to the study site and several anonymous reviewers for providing valuable 
comments that greatly improved the quality of this manuscript. Assistance in the field was provided by Breken Davis, Chris Dearner, Greg Hein, Mary Hicks, Stephanie Strickland, and Abby Tobin

\section{REFERENCES}

Bahia G.R. \& Ferreira R.L., 2005 - Influência das características físicoquímicas e da material orgânica de depósitos recentes de guano de morcego na riqueza e diversidade de invertebrados de uma caverna calcária. Revista Brasileira de Zoociências, 7: 143-164.

Barr T.C. \& Kuehne R.A., 1971 - Ecological studies in the Mammoth Cave system of Kentucky. II. The ecosystem. Annales de Spéléologie, 26: 47-96.

Benjamini Y. \& Hochberg Y., 1995 - Controlling the false discovery rate: a practical and powerful approach to multiple testing. Journal of the Royal Statistical Society, 57: 289-300.

Braak C.J.F. ter \& Şmilauer P., 2002 - CANOCO Reference Manual CanoDraw for Windows User's Guide. Software for Canonical Community Ordination (version 4.5). Ithaca (USA). http://www.pri.wur.nl/uk/products/canoco/

Bull E.G. \& Mitchell R.W., 1972 - Temperature and relative humidity responses in two Texas cave-adapted millipedes, Cambala speobia (Cambalida: Cambalidae) and Speodesmus bicornourus (Polydesmida: Vanhoeffeniidae). International Journal of Speleology, 4: 365-393. http://dx.doi.org/10.5038/1827-806X.4.3.7

Cayan D.R., Maurer E.P., Dettinger M.D., Tyree M. \& Hayhoe K., 2008 - Climate change scenarios for the California region. Climate Change, 87 (Supp1 1): S21-S42. http://dx.doi.org/10.1007/s10584-007-9377-6

Cigna A.A., 2002 - Modern trend in cave monitoring. Acta Carsologica, 31: 35-54.

http://carsologica.zrc-sazu.si/?stran=article\&id $=148$

Crouau-Roy B., Crouau Y. \& Ferre C., 1992 - Dynamic and temporal structure of the troglobitic beetle Speonomus hydrophilus (Coleoptera: Bathysciinae). Ecography, 15: 12-18.

http://dx.doi.org/10.1111/j.1600-0587.1992.tb00002.x

Culver D.C., 1970 - Analysis of simple cave communities: Niche separation and species packing. Ecology, 51: 949-958. http://dx.doi.org/10.2307/1933622

Culver D.C., Fong D.W. \& Jernigan R.W., 1991 - Species interactions in cave stream communities: experimental results and microdistribution effects. American Midland Naturalist, 126: 364-379.

http://dx.doi.org/10.2307/2426112

Culver D.C., Jones W.K. \& Holsinger J.R., 1992 - Biological and hydrological investigation of The Cedars, Lee County, Virginia, an ecologically significant and threatened karst area. In: Stanford J.A. \& Simons J.J. (Ed.) - Proceedings of the First International Conference on Ground Water Ecology. Bethesda (USA): United States Environmental Protection Agency, American Water Resources Association, \& Ecology Society of America: 281-290.

Culver D.C. \& Sket B., 2002 - Biological monitoring in caves. Acta Carsologica, 31: 55-64

Culver D.C., 2005a - Ecotones. In: Culver D.C. \& White W.B. (Eds.) - Encyclopedia of caves. Amsterdam: Elsevier: 206-208.

Culver D.C., 2005b - Species interactions. In: Culver D.C. \& White W.B. (Eds.) - Encyclopedia of caves. Amsterdam: Elsevier: 539-543.

Culver D.C. \& Pipan T., 2009 - The biology of caves and other subterranean habitats. Oxford University Press, Oxford, 256 p.
Dole-Olivier M-J. \& Marmonier P., 1992 - Effects of spates on the vertical distribution of the interstitial community. Hydrobiologia, 230: 49-61.

http://dx.doi.org/10.1007/BF00015114

Ferreira R.L. \& Martins R.P., 1998 - Diversity and distribution of spiders associated with bat guano piles in Morrinho Cave (Bahia State, Brazil). Diversity and Distributions, 4: 235-241

Ferreira R.L., Martins R.P. \& Yanega D., 2000 - Ecology of bat guano arthropod communities in a Brazilian dry cave. Ecotropica, 6: 105-116.

Ferreira R.L., Prous X. \& Martins R.P., 2007 - Structure of bat guano communities in a dry Brazilian cave. Tropical Zoology, 20: 55-74.

Fryer, S., 2001. Map of Clough Cave, Sequoia National Park, California.

Fong D.W. \& Culver D.C., 1994 - Fine-scale biogeographic differences in the crustacean fauna of a cave system in West Virginia, USA, 287: 29-37.

Howarth F.G., 1980 - The zoogeography of specialized cave animals: a bioclimatic model. Evolution, 34: 394-406.

Juberthie C., Delay B. \& Bouillon M., 1980 -Sur l'existence du milieu souterrain superficiel en zon non calcaire. Comptes Rendus de l'Académie des Sciences de la France D, 290: 49-52.

Krejca J., 2006 - Inventory of karst fauna in Sequoia, Kings Canyon, and Yosemite National Parks, final report, Contract No. P8558602608. Zara Environmental LLC, Buda (USA), 156 p.

Lencioni V., Bernabò P. \& Latella L., 2010 - Cold resistance in two species of cave-dwelling beetles (Coleoptera: Cholevidae). Journal of Thermal Biology, 35: 354-359. http://dx.doi.org/10.1016/j.jtherbio.2010.07.004

Narum S.R., 2006 - Beyond Bonferroni: Less conservative analyses for conservation genetics. Conservation Genetics, 7: 783-787.

http://dx.doi.org/10.1007/s10592-005-9056-y

Novak T., Perc M., Lipovšek, S. \& Janžekovič, F., 2012 Duality of terrestrial subterranean fauna. International Journal of Speleology, 41: 181-188. http://dx.doi.org/10.5038/1827-806X.41.2.5

Owen J.G., 1989 - Patterns of herpetofaunal species richness: relation to temperature, precipitation, and variance in elevation. Journal of Biogeography, 16: 141-150. http://dx.doi.org/10.2307/2845088

Peck S.B., 1976 - The Effect of cave entrances on the distribution of cave-inhabiting terrestrial arthropods. International Journal of Speleology, 8: 309-321. http://dx.doi.org/10.5038/1827-806X.8.4.1

Pipan T., Christman M.C. \& Culver D.C., 2006 Dynamics of epikarst communities: microgeographic pattern and environmental determinants of epikarst copepods in Organ Cave, West Virginia. American Midland Naturalist, 156: 75-87. http://dx.doi. org/10.1674/0003-0031(2006)156[75:DOECMP]2.0.CO;2

Pipan T., López H., Oromí P., Polak S. \& Culver D.C., 2010 - Temperature variation and the presence of troglobionts in terrestrial shallow subterranean habitats. Journal of Natural History, 45: 253-273. http://dx.doi.org/10.1080/00222933.2010.523797

Pörtner H.O. \& Ferrell A.P., 2008 - Physiology and climage change. Science, 31: 690-692. http://dx.doi.org/10.1126/science.1163156

Poulson T.L., 2005 - Food sources. In: Culver D.C. \& White W.B. (Ed.) - Encyclopedia of caves. Amsterdam: Elsevier: 255-264.

Prous X., Ferreira R.L. \& Martins R.P., 2004 - Ecotone delimitation: epigean-hypogean transition in cave ecoystems. Austral Ecology, 29: 374-382.

http://dx.doi.org/10.1111/j.1442-9993.2004.01373.x 
R Development Core Team, 2012 - R: A language and environment for statistical computing. $R$ Foundation for Statistical Computing. Vienna (Austria).

http://www.R-project.org

Racoviță E.G., 2006 - Essay on biospeleological problems (D.C. Culver and O.T. Moldovan, trans.). In: Moldovan O.T. (Ed.) - Emil Racovitza. Essay on biospeleological problems - French, English, Romanian version. ClujNapoca (Romania): Casa Cărți de Ştiință: 127-183.
Sager P.E. \& Hasler A.D., 1969 - Species diversity in lacustrine phytoplankton. I. The components of the index of diversity from Shannon's formula. The American Naturalist, 103: 51-59.

http://dx.doi.org/10.1086/282581

Sendra A. \& Reboleira A.S.P.S., 2012 - The world's deepest subterranean community - Krubera-Voronja Cave (Western Caucasus). International Journal of Speleology, 41: 221-230. http://dx.doi.org/10.5038/1827-806X.41.2. 